\title{
Flow Analysis for Single and Multi-Nozzle Jet Pump*
}

\author{
Tadashi NARABAYASHI*****, Yukitaka YAMAZAKI**, \\ Hidetoshi KOBAYASHI ${ }^{* * * *}$ and Toshihiko SHAKOUCHI ${ }^{\dagger}$
}

\begin{abstract}
Jet pumps, driven by a Primary-Loop Recirculation (PLR) Pump, have been widely used in Boiling Water Reactor (BWR) plants to recirculate the reactor core coolant. A jet pump consists of a driving nozzle, a bell-mouth, a throat and a diffuser. The improvement of the jet pump efficiency for BWR plants brings an economic advantage because it reduces the operating power cost of the PLR pump. In order to improve the efficiency of the BWR jet pump, a $1 / 5$ scale jet pump test loop for BWR plant was used and intensive tests were conducted focusing on the types of driving nozzles and shapes of the throat. These test data were used for CFD flow analysis code verification. The analytical data showed good agreement with the test results. After the analytical model verification, improvement of jet pump efficiency was conducted. It was shown by the CFD analysis that the peak efficiency of the improved jet pump will be $36 \%$ with the tapered throat.
\end{abstract}

Key Words: Jet Pump, Nozzle, Pressure Distribution, Turbulent Mixing, Nuclear Reactor, Power Plant, CFD Code, Boiling Water Reactor (BWR), Primary Recirculation Loop (PLR)

\section{Introduction}

A jet pump is a passive pump that consists of a driving nozzle, a bell-mouth, a throat and a diffuser. The throat has an appropriate length to mix the driving jet and the induced flow, but large friction loss occurs in the long throat because of its length and flow rate.

Jet pumps have been widely used in Boiling Water Reactor (BWR) plants, driven by the PLR pump to recirculate the reactor core coolant, because of their safety aspects by minimizing the PLR piping diameter and pump flow. The improvement of efficiency of the BWR jet pump brings an economic advantage because it reduces the operating power cost of the PLR pump for driving jet flow $^{(1)-(4)}$.

In order to improve the efficiency of the BWR jet pump, this study focuses on the number of nozzles and

* Received 31st March, 2006 (No. 06-4069)

** TOSHIBA Corporation, 8 Shinsugita-cho, Isogo-ku, Yokohama 235-8523, Japan

*** Present Address, Graduate School of Engineering, Hokkaido University, Nishi 8, Kita 13, Kita-ku, Sapporo 0608628, Japan. E-mail: tnaraba@eng.hokudai.ac.jp

**** Chubu Electric Power Co., Inc., 1 Higashishinmachi, Higashi-ku, Nagoya-shi 461-8680, Japan

$\dagger$ Graduate School of Engineering, Mie University, 1577 Kurimamachiya-cho, Tsu-shi, Mie 514-8507, Japan mixing process between the driving jet and suction flow into the throat by using the flow analysis. For this purpose, a single nozzle or a five-nozzles were used with the straight throat or the tapered throat for the analysis. The effects of the nozzle types and throat shapes with surfaceroughness on the jet pump efficiency were examined using the analytical results.

\section{Jet Pump Test Loop}

Figure 1 shows the jet pump test loop used in this study. The size of the test jet pump was about $1 / 5$ the scale of the current BWR jet pump. The test jet pump consists of a drive-nozzle, a throat with an inlet bell-mouth and a

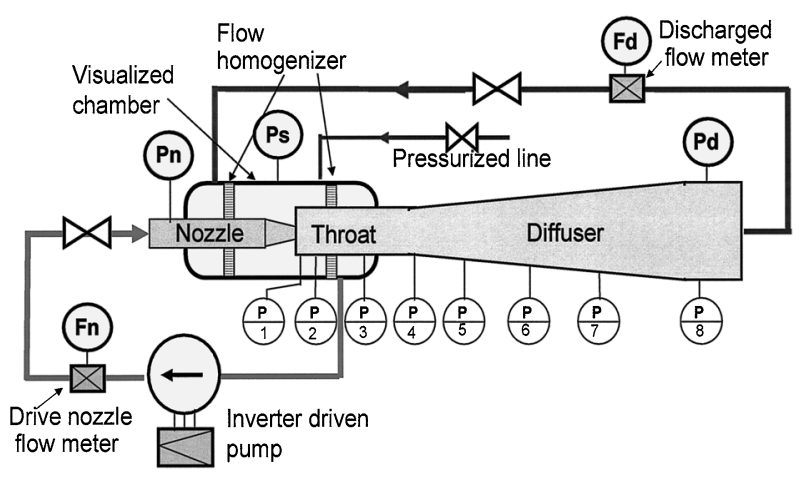

Fig. 1 The $1 / 5$ scale jet pump test loop for BWR plant 
conical-diffuser. An inverter driven centrifugal pump was used to drive the jet pump injecting discharged pressure up to $1.6 \mathrm{MPa}$ into the drive-nozzle. A water jet discharged from the drive-nozzle was transferred to the suction flow in the throat. Figure 2 shows the outer dimensions of the jet pump test loop, and Fig. 3 shows an external view of the jet pump test loop and dimensions of the test jet pump.

There are two-types of drive-nozzles concerning the number of nozzles. One is a single-nozzle and the other is a five-nozzles as shown in Fig. 4. The inner diameter of the single-nozzle's exit was $17 \mathrm{~mm}$, and that of the fivenozzles was $8 \mathrm{~mm}$. The flow areas of the single-nozzle and the five-nozzles were almost the same at about $250 \mathrm{~mm}^{2}$ to examine the nozzle numbers. The inner diameter and the flow area of the throat were $35 \mathrm{~mm}$ and $950 \mathrm{~mm}^{2}$ respectively.

The area-ratio called the R-ratio was about 0.25 . In the jet pump studies, the M-ratio (mass flow ratio) and the N-ratio (pressure ratio) were commonly used to compare the jet pump performance. Multiplication of $M$ and $N$ gives the jet pump efficiency $\eta$. The M-ratio and N-ratio

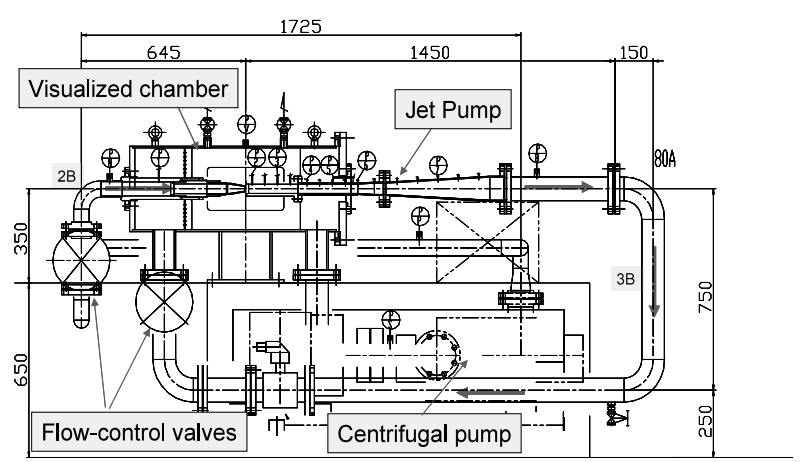

Fig. 2 Outer dimensions of the jet pump test loop
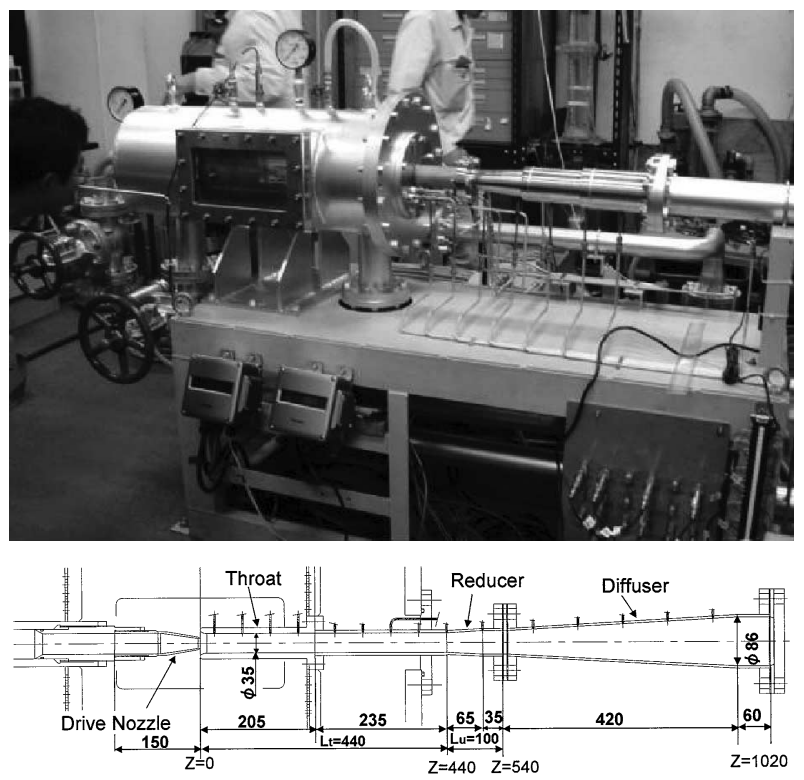

Fig. 3 External view of the jet pump test loop are defined as follows ${ }^{(1)}$

$$
\begin{aligned}
& M=Q_{s} / Q_{n} \\
& N=\left(P_{d}-P_{s}\right) /\left(P_{n}-P_{d}\right) \\
& \eta=M \cdot N
\end{aligned}
$$

where, $Q$ is the volumetric flow rate $\left(\mathrm{m}^{3} / \mathrm{s}\right)$ of the water and $P$ is a total pressure (MPa). Subscript $n$ means drivenozzle, $s$ means suction and $d$ means the discharge of the diffuser. The scale ratio of the $1 / 5$ of the current BWR jet pump gives $1 / 25$ flow rate in the test loop.

As shown in Fig. 5 of the jet pump throat configuration, two types of throat were used. The normal throat consists of an $L_{t}=440 \mathrm{~mm}$ straight part and a diffuser part $\left(2 \theta_{u}=6 \mathrm{deg}, L_{u}=100 \mathrm{~mm}\right)$. The tapered throat con-

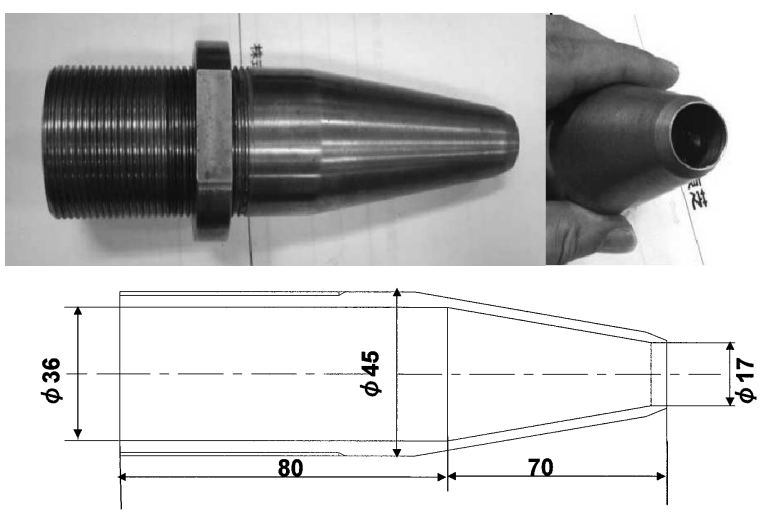

(a) A single nozzle
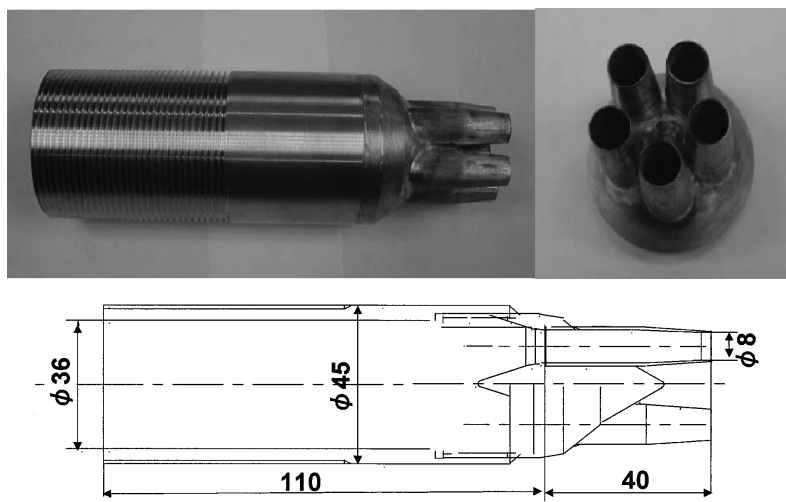

(b) A five-nozzle

Fig. 4 Tested drive-nozzles for the jet pump

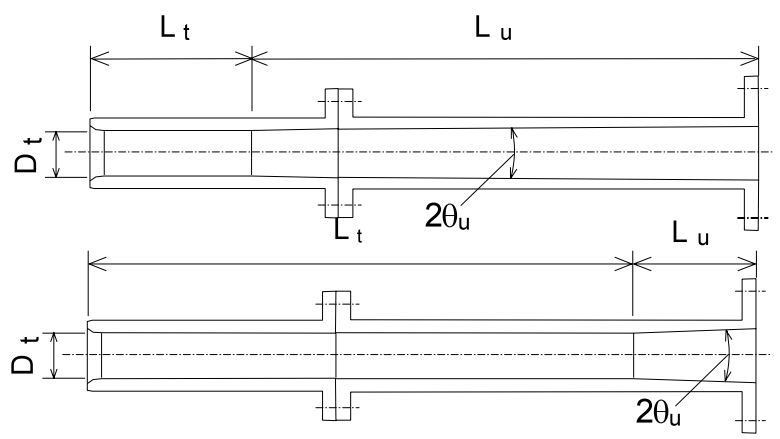

Fig. 5 A normal throat and modified tapered throat 
sists of an $L_{t}=130 \mathrm{~mm}$ straight part and $2 \theta_{u}=1.0 \mathrm{deg}$, $L_{u}=410 \mathrm{~mm}$ tapered part. The inner diameter of each straight part is $D_{t}=35 \mathrm{~mm}$.

In order to set the drive-nozzle at proper position 's', determination tests were conducted by changing the nozzle distance between the drive-nozzle exit and the inlet of bell-mouth, as shown in Fig. 6. M-ratio $M$ was calculated by using Eq. (1). A rated flow rate of the drivenozzle flow and the suction flow for a jet pump installed in an actual BWR are about $0.3 \mathrm{~m}^{3} / \mathrm{s}$ and $0.35 \mathrm{~m}^{3} / \mathrm{s} \mathrm{respec-}$ tively, the rated M-ratio is about $0.035 / 0.03=1.2$. The rated drive-nozzle flow rate of the $1 / 5$ scale test loop is $0.03 / 5^{2}=12 \times 10^{-3} \mathrm{~m}^{3} / \mathrm{s}$. But the almost all the tests were conducted under the condition of $6.5 \times 10^{-3} \mathrm{~m}^{3} / \mathrm{s}$ drivenozzle flow rate to prevent the water temperature increase during a test measurement.

For example, a case of M-ratio was 1.2, the discharge flow rate was adjusted to $Q_{d}=Q_{s} \cdot(1+M)=6.5 \times$ $10^{-3} \mathrm{~m}^{3} / \mathrm{s} \times 2.2=14.3 \times 10^{-3} \mathrm{~m}^{3} / \mathrm{s}$ by using the discharge flow control valve. The measured data of drive-nozzle pressure $P_{n}$ was about $0.62 \mathrm{MPa}$ and the discharge pressure $P_{d}$ of the test jet pump was about $0.30 \mathrm{MPa}$ and the suction chamber pressure $P_{s}$ was about 0.23 . The $\mathrm{N}$-ratio $N$ is given by Eq. (2).

$$
\begin{aligned}
N & =\left(P_{d}-P_{s}\right) /\left(P_{n}-P_{d}\right) \\
& =(0.30-0.23) /(0.62-0.30)=0.22 .
\end{aligned}
$$

The efficiency of the test jet pump was given by Eq. (3).

$$
\eta=M \cdot N=1.2 \times 0.22=0.26
$$

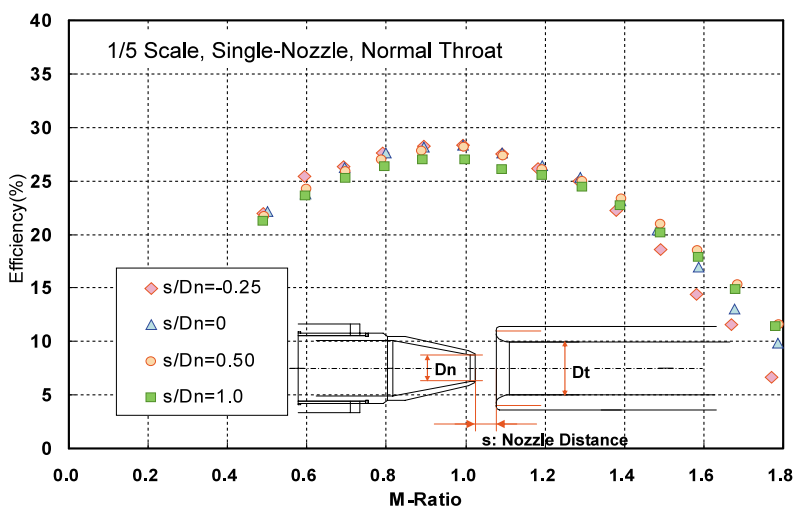

Fig. 6 Effect of nozzle position on efficiency
If the discharge pressure increased from 0.30 MPa to $0.31 \mathrm{MPa}, \mathrm{N}$-ratio becomes 0.258 and the efficiency improved from $26 \%$ to $31 \%$. Therefore, we choose pressure sensors which have $0.1 \%$ accuracy of $1 \mathrm{MPa}$ rated pressure. The flow rate was measured by using electromagnetic flow meter of $1 \%$ accuracy.

By reviewing the Fig. 6, it was found that the best nozzle position is $s=0$. In the case of $s=1.0$, the peak efficiency is degraded about $1 \%$. In case of the drive-nozzle top is in the bell-mouth $(s=-0.5)$, efficiency was degraded at higher M-ratio of $M>1.3$.

\section{Analysis of Jet Pumps}

\subsection{Analysis of the single-nozzle jet pump test}

The CFD analysis code used in this study was StarCD with standard $\mathrm{k}-\varepsilon$ turbulent with wall friction model. In our experience, the CFD code gives valid results at higher Re number. The analytical mesh and boundary conditions for the single-nozzle jet pump are shown in Fig. 7. The working fluid is water at measured temperature for the test analysis. There are two inlet boundary. One is the drive-nozzle boundary and the other is the suction chamber boundary. Each boundary gives the pressure and the flow rate of measured data. The outlet boundary is a discharge pipe attached with the diffuser of the test jet pump. At the throat inlet, a fine mesh was used to evaluate the driving jet flow at the bell-mouth. In addition, the surface roughness boundary was assumed to be $25 \mu \mathrm{m}$ based on the machined surface roughness.

Figure 8 shows the analytical results of pressure distribution and velocity distribution. The boundary conditions for the analysis was shown in the figure. The velocity vector and velocity contours in Fig. 8 show that momentum of a high-speed water jet was transferred to the suction flow from the bell-mouth to the end of throat by turbulent mixing. A static pressure contour shows that there is a low-pressure region in the throat, and that the throat was too long. We consider that a throat has an appropriate mixing length concerning the friction loss along the long throat under rated flow rate.

Figure 9 (a) shows the comparison of static pressure distribution between the analytical results and the test re-

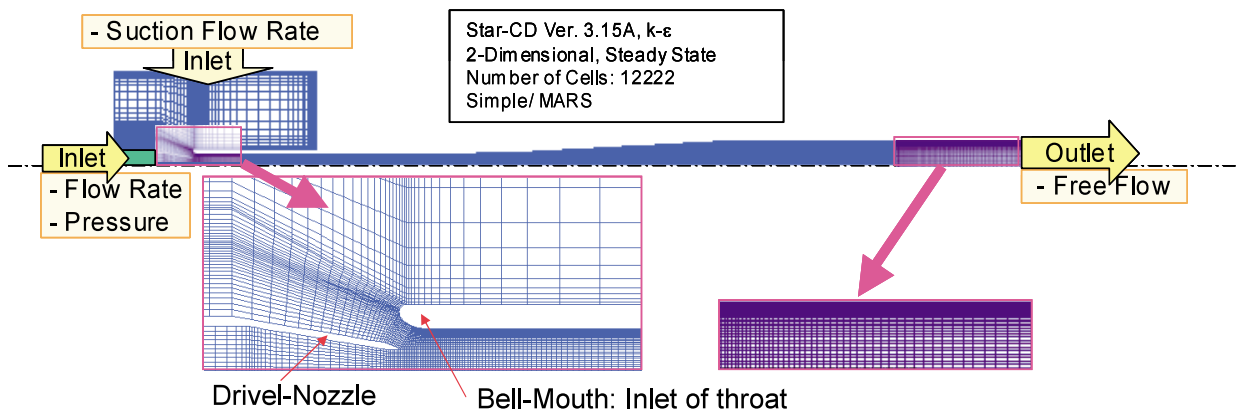

Fig. 7 An analytical mesh and boundary conditions for the single-nozzle 


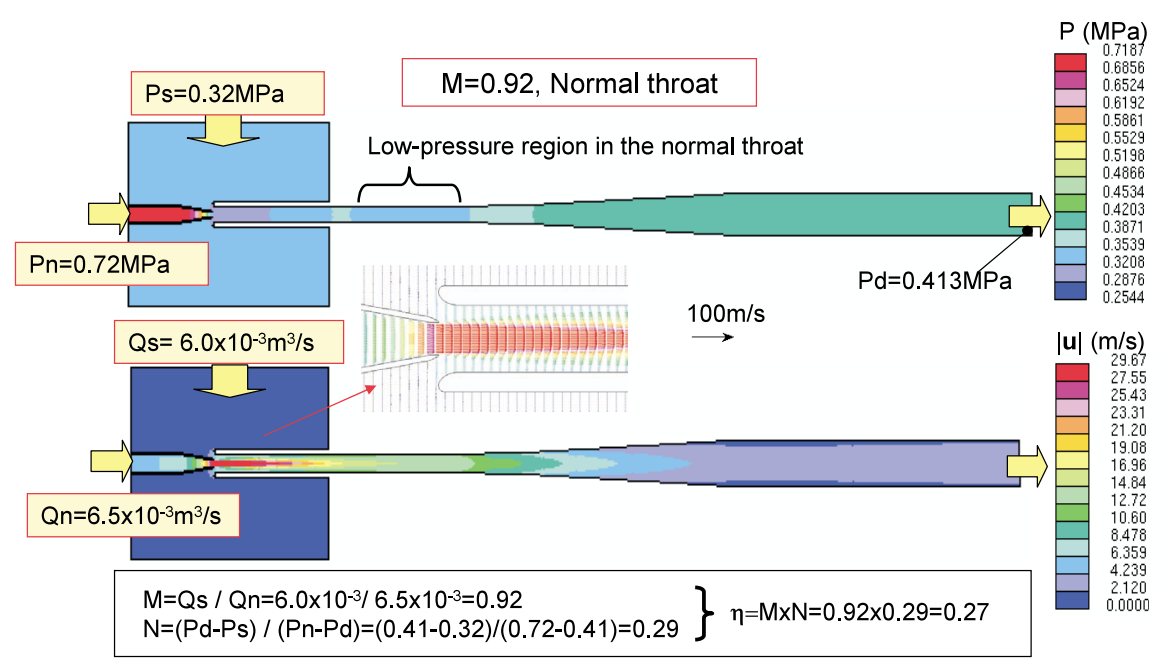

Fig. 8 Analytical results of the single nozzle ( $1 / 5$ Scale, Normal throat, $M=0.92)$

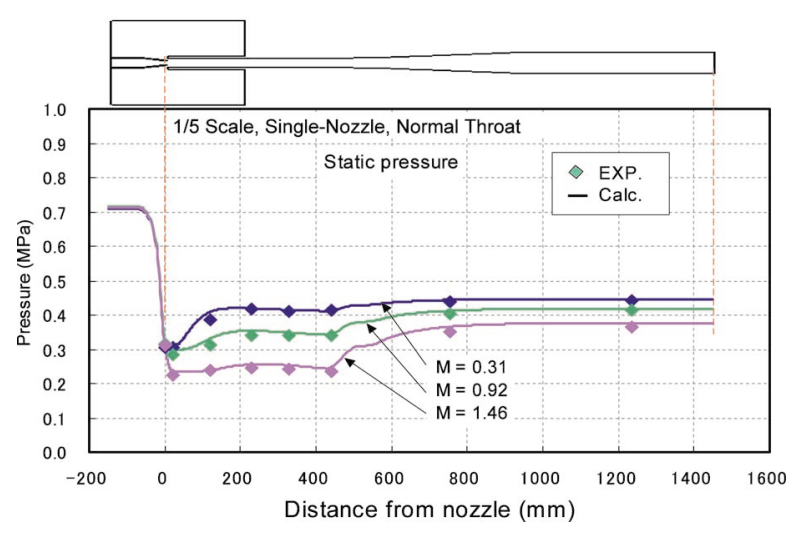

(a) Pressure distribution

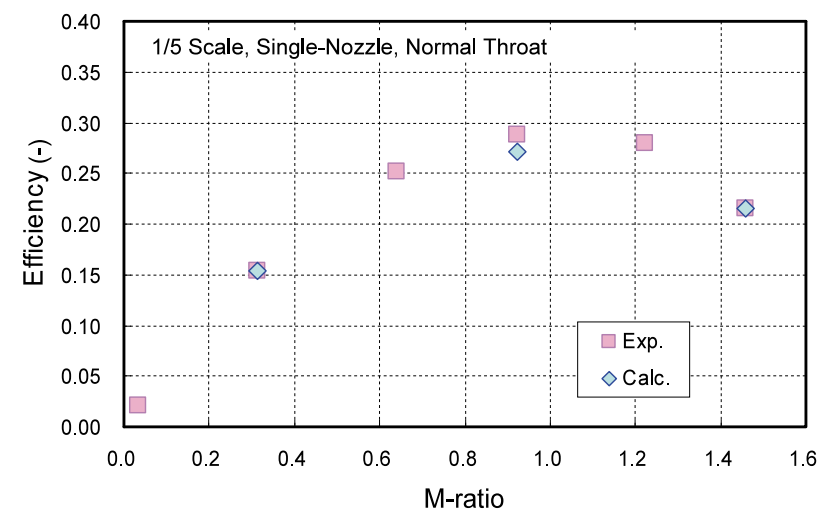

(b) Jet pump efficiency

Fig. 9 Comparison of the single-nozzle test jet pump between analysis and test data

sults. The analytical results show good agreement with the test data.

Figure 9(b) shows a comparison of the analysis and test data of the jet pump efficiency for the single nozzle. Each data shows good agreement with the experimental data. It was confirmed that the analysis model gives valid results.

After the analytical model verification, improve anal-

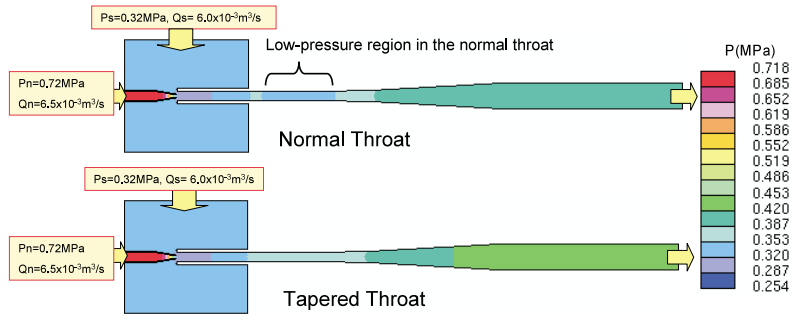

(a) Pressure distribution $(M=0.92)$

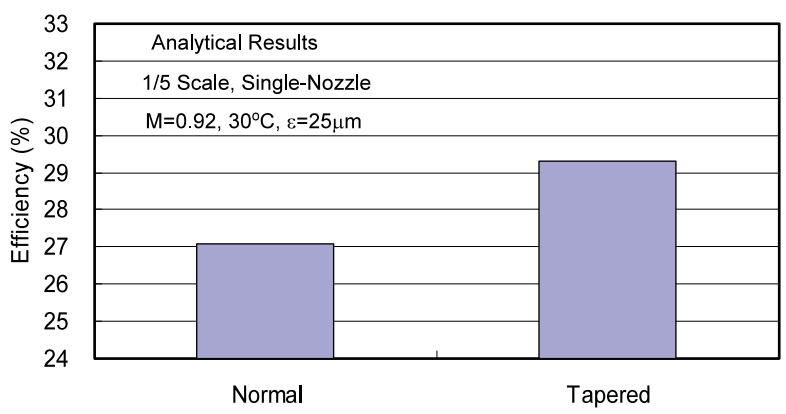

(b) Jet pump efficiency

Fig. 10 The effect of throat shape

ysis for tapered throat was conducted. The shape of the tapered throat is shown in Fig. 5. As shown in Fig. 10 (a), in the case of tapered throat, the low-pressure region in the throat was disappeared. Figure 10 (b) shows the effect of throat shape on the jet pump efficiency. The jet pump efficiencies were improved from 27 to $29 \%$. It was suggested by the analysis that a throat has an appropriate mixing length concerning the friction loss with velocity increase near the throat wall by the momentum transfer from drive-flow to suction-flow. If an inner diameter of a throat increased $1 \%$, the cross-section of the throat increased $(1.01)^{2}=2 \%$, pressure loss decreased $1 / u^{2}=1 /(1.01)^{4}=96 \%$. Thus, the inner diameter is very sensitive to the jet pump efficiency. A patent has been applied for the tapered throat. 


\subsection{Analysis of the five-nozzle test}

Figure 11 shows the analytical models of the fivenozzles jet pump. The jet pump model consists of a five-nozzles mesh made from a 3-D CAD model, a throat mesh, a diffuser and a suction chamber mesh. The sector size was $360 /(5 \times 2)=36 \mathrm{deg}$. These meshes were built up into one model to conduct the analysis as shown in Fig. 11 (f).

Figure 12 shows the analytical results of the fivenozzles jet pump showing the axial velocity contour. The water jets from the five-nozzles were mixed in the throat along the axial direction, and the water jet approached near the throat wall. The phenomenon was very similar to the previous visualized test date as shown in Fig. 13.

As shown in Fig. 14, though the pressure distribution of the test data in the throat were slightly above the ana- lytical results, discharge pressure of jet pump show good agreement with the test data for $M=0.4,0.8,1.2$. The small difference between the test data and analytical data seemed to be caused by the 3-D effect of the multiple jet form the five-nozzles jet. It depended on the pressure taps configuration with the jets. Comparison between

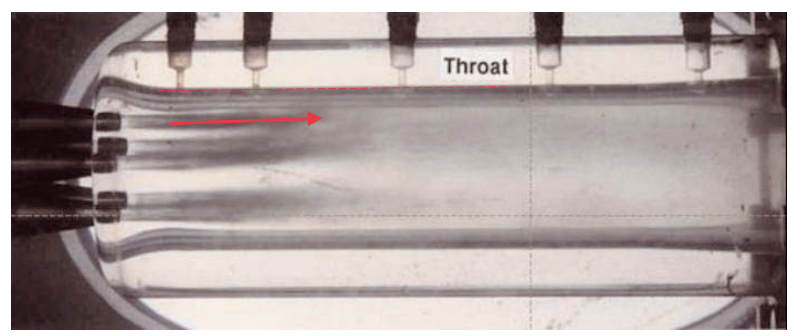

Fig. 13 A visualized result of the five-nozzles jet pump ${ }^{(2)}$

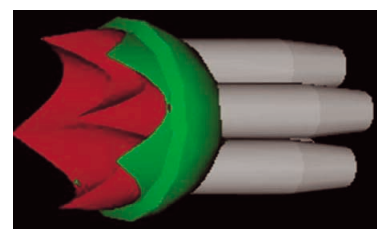

(a) 3-D CAD model of the five-nozzles

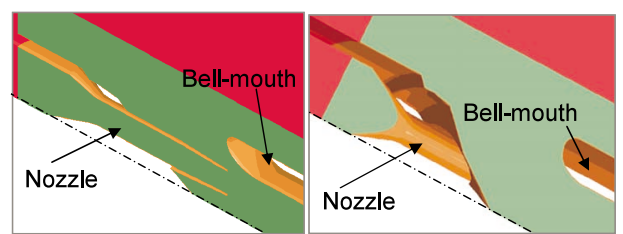

(c) 3-D solid model of the five-nozzles
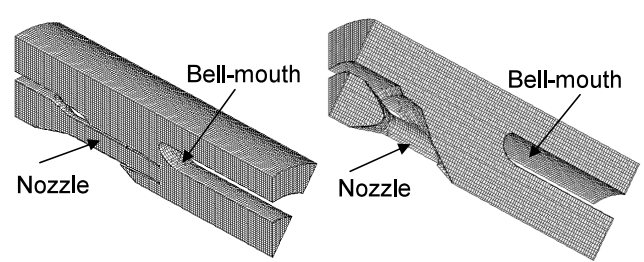

(d) 3-D mesh of the five-nozzles into the jet pump mesh

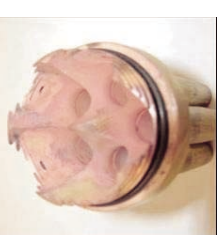

(b) Test nozzle 


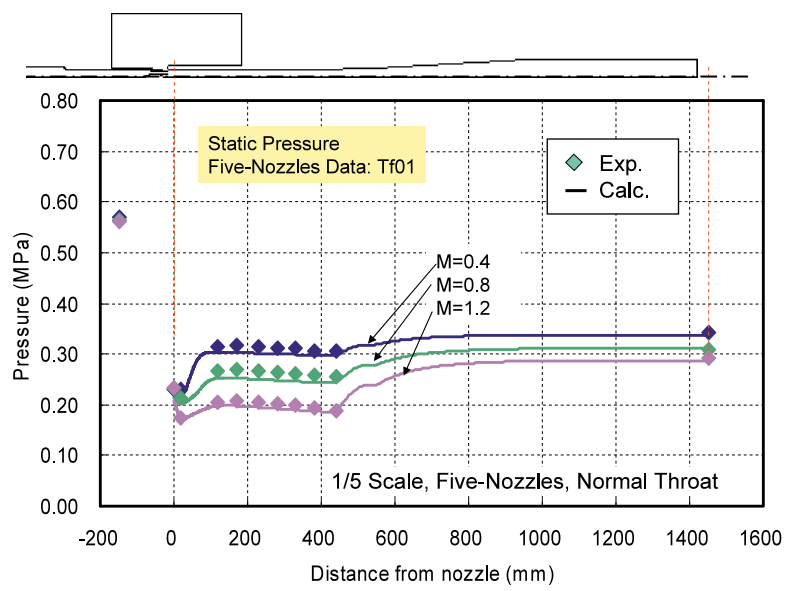

(a) Pressure distribution

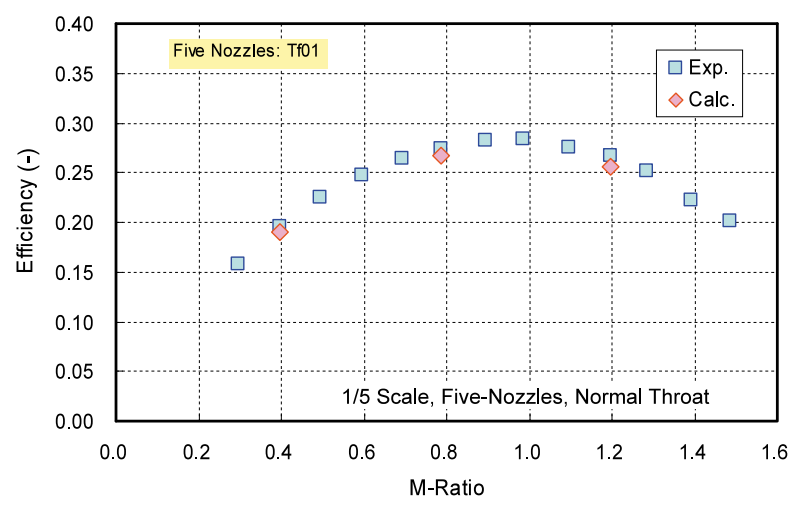

(b) Jet pump efficiency

Fig. 14 Comparison of the single-nozzle test jet pump between analysis and test data

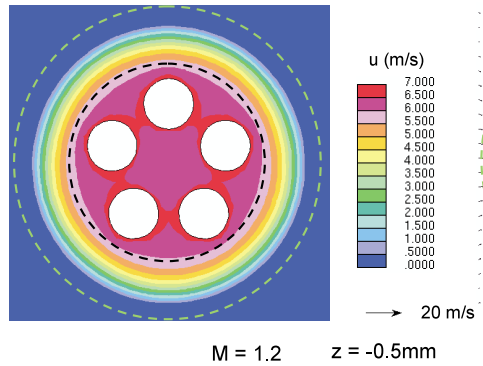

(a) Axial velocity contour

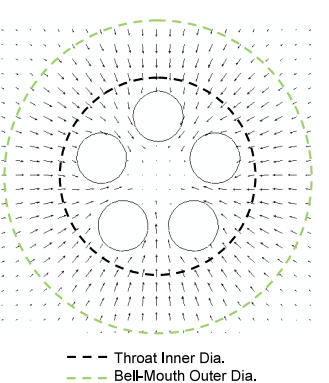

(b) Radial velocity vector
Fig. 15 Comparison of efficiency with the test and analysis results
Figs. 9 (b) and 14 (b) shows that the efficiency of the fivenozzles jet pump was not so good in the case of a low M-ratio jet pump, such as $M<2$. In the case of a fivenozzles jet pump which has a peak efficiency at $M=2.2$, the peak efficiency exceeds over $40 \%$. The reason for the low-efficiency may be caused by an inlet flow resistance between the nozzle fingers and bell-mouth. As shown in Fig. 15 (a), there are high axial velocity regions between the nozzle fingers. Figure 15 (b) shows that a low radial velocity region exists at the center of the five-nozzles. The region does not contributes to accelerate the suction flow.

\subsection{Full size jet pump analysis}

After checking the code verification, full size jet pump analysis was conducted, by using the same mesh models, but simply scaling up the dimension data 5 times. The reason why we used the same mesh models was to obtain the similar pressure gradient and velocity gradient for each mesh width.

Figure 16 shows a comparison of the scaling effect on the axial velocity contour with $1 / 5$ scale and $1 / 1$ scale. The flow-pattern of the axial velocity contour seems almost the same. Figure 17 shows the comparison of scaling effect on efficiency with $1 / 5$ scale and $1 / 1$ scale. The efficiency was improved from $27 \%$ to $32 \%$ by the scale up. If the surface-roughness is the same, the relative roughness ratio is reduced $1 / 5$. This is the main reason for the efficiency improvement.

Figure 18 shows an efficiency curve of the modified throat for the $1 / 1$ scale jet pump, the peak efficiency was increased to $36 \%$. As shown in Fig. 19, the peak efficiency of the $1 / 1$ scale jet pump improved from $32 \%$ to $36 \%$.

\section{Effect of Surface Roughness}

In an actual jet pump in a BWR plant, some crud such as iron oxide or chromium oxide may attach to the innersurface of the jet pump. Therefore, we evaluated the effect of surface-roughness on the efficiency of full-scale jet pump.

As shown in Fig. 20, when the surface-roughness increased from $25 \mu \mathrm{m}$ to $100 \mu \mathrm{m}$, the efficiency of the jet

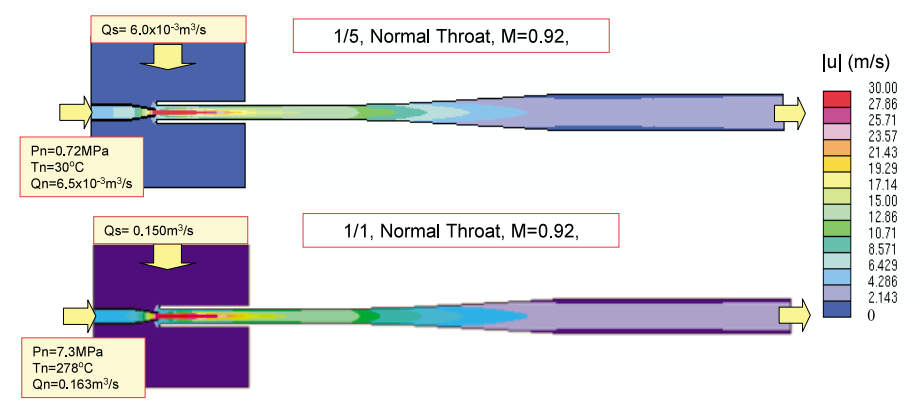

Fig. 16 Comparison of a scaling effect on axial velocity (Normal throat, Axial velocity contours) 


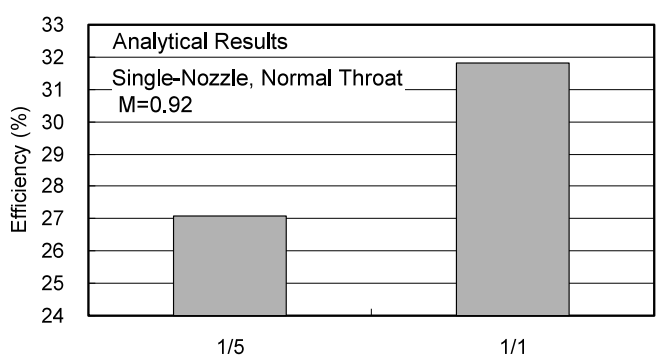

Fig. 17 Comparison of a scaling effect on efficiency

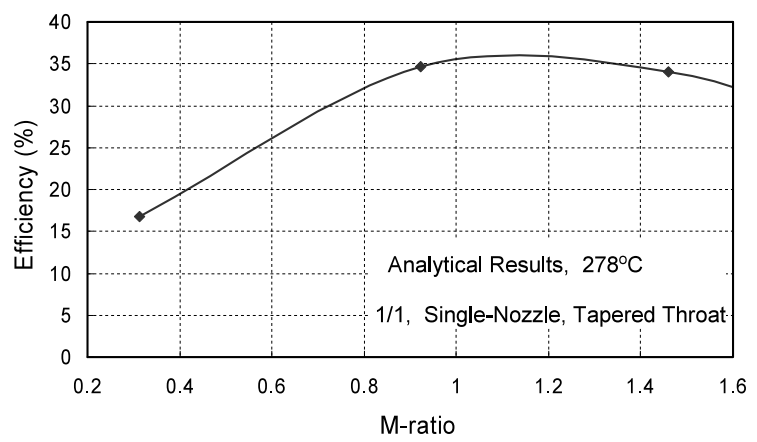

Fig. 18 Efficiency curve of modified jet pump (1/1 Scale)

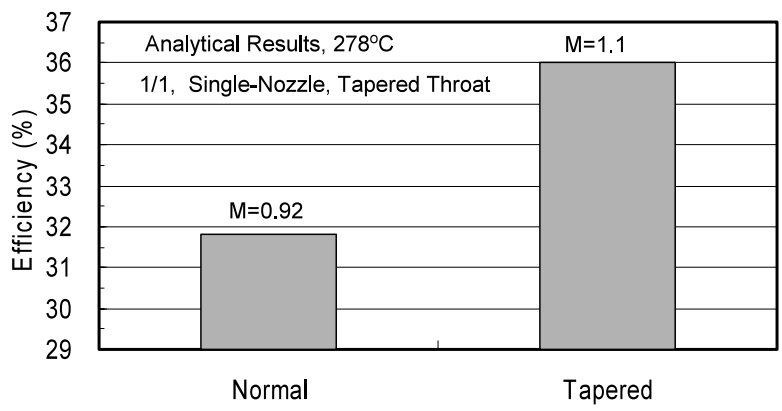

Fig. 19 Modified effect by tapered throat

pumps was decreased by about $4 \%$ for both the normal and the tapered throat jet pumps. Figure 21 shows the effect of surface-roughness on pressure distribution. It was found that the effect of the surface-roughness on pressure distributions occurred mainly in the throat.

Figure 22 shows the modified effect test by polishing the test tapered throat nozzle by fine machining to obtain $6.3 \mu \mathrm{m}$ standard roughnesses. The $6.3 \mu \mathrm{m}$ surfaceroughness of the $1 / 5$ scale test jet pump almost corresponds to the analytical results of the $1 / 1$ scale jet pump ( $25 \mu \mathrm{m}$ surface roughness). Thus, it was also shown by the scaled model test that the peak efficiency will be improved to $36 \%$ in the $1 / 1$ scale actual plant, by using the tapered throat.

\section{Conclusion}

In order to improve the efficiency of the BWR jet pump, a single nozzle or five nozzles with straight throat or tapered throat were analyzed. The effects of nozzle number, throat shapes, and surface-roughness on jet pump

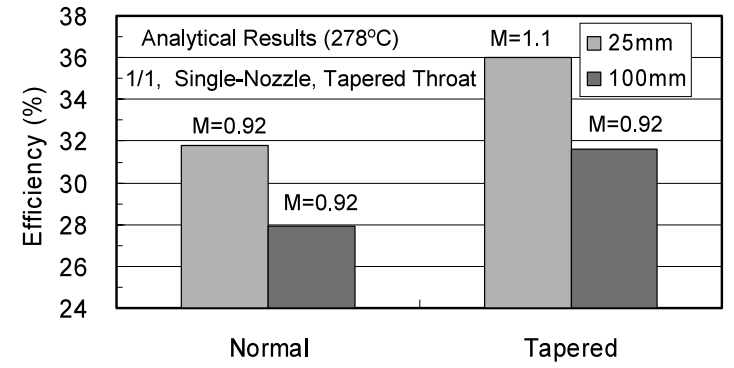

Fig. 20 Effect of surface-roughness on efficiency (1/1 Scale)

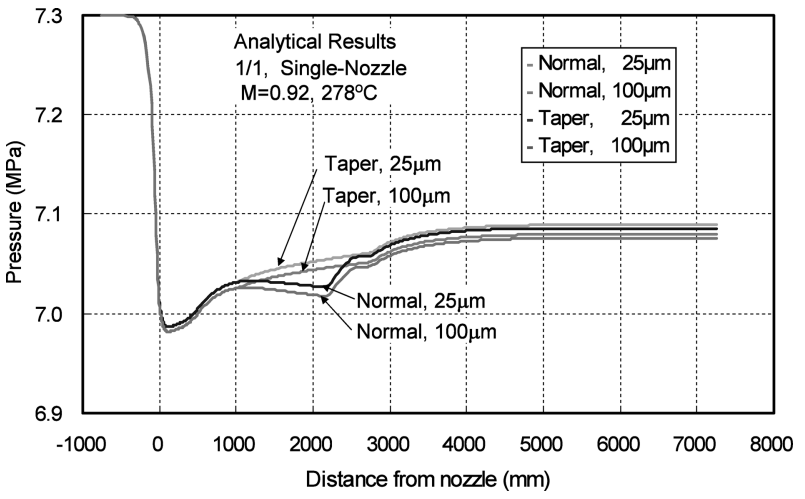

Fig. 21 Effect of surface-roughness on pressure distribution

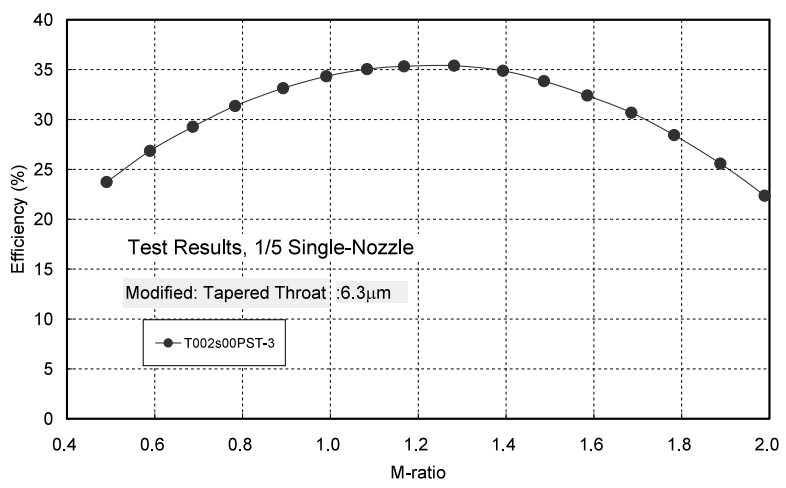

Fig. 22 Efficiency curve of modified jet pump (1/5 Scale)

efficiency were examined using the analysis results. These results show the advantage of the single-nozzle jet pump with the tapered throat. It was shown by the CFD analysis and $1 / 5$ scale model test that the peak efficiency of the improved jet pump will be $36 \%$.

\section{Acknowledgments}

This study was conducted as a joint study between Mie University, Chubu Electric Power Company and TOSHIBA Corporation. The authors express their gratitude to Mr. Shoji Takashi, Mr. Shigeru Hida and Mr. Shinichi Ishizato, Mr. Katsumasa Araoka, Mr. Masaki Inoue for their support to this study. The authors are grateful to Mr. Naofumi Shibata for his contribution to the StarCD analysis. 


\section{References}

( 1 ) Nei, H. and Narabayashi, T., Characteristics of Jet Pumps for Nuclear Reactors (1st Report, Basic Tests under High Temperature), Trans. Jpn. Soc. Mech. Eng., (in Japanese), Vol.60, No.569, B (1994), pp.194-200.

( 2 ) Narabayashi, T., Nei, H., Mizumachi, W., Nakajima, S. and Hayakawa, K., Analytical Study to Develop High Flow Ratio Jet Pumps, No.96-1, Proc. of 73rd Term, JSME Annual Meeting, (in Japanese), Vol.III (1996).

( 3 ) Nei, H., Iwaki, C., Narabayashi, T., Matsumoto, K.,
Iwanaga, S., Mizumachi, W. and Tanabe, A., Characteristics of Jet Pumps for Nuclear Reactors (2nd Report, Experiments for High Performance with High Flow ratio), Trans. Jpn. Soc. Mech. Eng., (in Japanese), Vol.62, No.601, B (1996), pp.134-139.

( 4 ) Yamazaki, Y., Yamazaki, A., Narabayashi, T., Suzuki, J. and Shakouchi, T., Studies on Mixing Process and Performance Improvement of Jet Pump, Trans. Jpn. Soc. Mech. Eng., (in Japanese), Vol.71, No.701, B (2005), pp.147-153. 